\title{
Immune RECIST criteria and symptomatic pseudoprogression in non-small cell lung cancer patients treated with immunotherapy
}

\author{
Martina Vrankar ${ }^{1}$, Mojca Unk² \\ ${ }^{1}$ Department of Radiotherapy, Institute of Oncology Ljubljana, Ljubljana, Slovenia \\ ${ }^{2}$ Department of Medical Oncology, Institute of Oncology Ljubljana, Ljubljana, Slovenia
}

Radiol Oncol 2018; 52(4): 365-369.

Received 5 February 2018

Accepted 12 March 2018

Correspondence to: Martina Vrankar, M.D., Ph.D., Institute of Oncology Ljubljana, Zaloška 2, 1000 Ljubljana, Slovenia. Phone: +386 15879 629; Fax: +386 15879 400, E-mail: mvrankar@onko-i.si

Disclosure: No potential conflicts of interest were disclosed.

Background. Uncommon response during immunotherapy is a new challenging issue in oncology practice. Recently, new criteria for evaluation of response to immunotherapy immune response evaluation criteria in solid tumors (iRECIST) were accepted. According to iRECIST, worsening of performance status (PS) accompanied to pseudoprogression reflects most probably the true progression of the malignant disease.

Methods. A systematic review of the literature was made by using several electronic database with the following search criteria: symptomatic pseudoprogression, atypical response, immunotherapy and lung cancer.

Results. In the literature, we identified five reports of seven patients treated with immunotherapy that met the inclusion criteria. We also report our experience of patient with pseudoprogression and almost complete response after one dose of immunotherapy.

Conclusions. As seen from our review, iRECIST criteria might be insufficient in distinguishing true progression from pseudoprogression in some patients with advanced NSCLC treated with immunotherapy. More precise assessment methods are urgently needed.

Key words: symptomatic pseudoprogression; atypical response; immunotherapy; lung cancer

\section{Introduction}

Immunotherapy is a new therapeutic strategy for increasing number of malignancies including non small-cell lung cancer (NSCLC). Check point inhibitors affecting programmed death 1 /programmed death ligand 1 (PD-1/PD-L1) signaling pathway have become key drugs against metastatic NSCLC..$^{1-5}$ Since the action of check point inhibitors is different from cytotoxic and targeted therapy also the responses to immunotherapy could be atypical.

One of unexpected response named pseudoprogression, which is characterized by radiologic enlargement of the tumor burden, followed by regression or appearance of new lesions, was first recognized in metastatic melanoma patients treat- ed with ipilimumab.6.7 Pseudoprogression was observed in up to $10 \%$ of melanoma patients progressing on immunotherapy and is associated with favorable long-term survival. ${ }^{8}$ Radiologic pseudoprogression in patients with metastatic NSCLC treated with anti-PD-1/PD-L1 therapy is reported less common than in melanoma patients in the range of $0-6 \% .^{9-15}$

Standard for the evaluation of radiologic response of the tumors to treatment is response evaluation criteria in solid tumors (RECIST) system 1.1.16 Recently, after few immune adjusted criteria in the past, new criteria for evaluation of response to immunotherapy immune RECIST (iRECIST) were proposed and accepted. ${ }^{7}$ Most important change in iRECIST is requirement for confirmation of tumor enlargement after a minimum of 4 weeks and no 
later than 8 weeks from the last evaluation. Related to this, new terminus for unconfirmed (iUCD) and confirmed progressive disease (iCPD) were accepted. Some other aspects are highlighted in iRECIST regarding pseudoprogression. Worsening of clinical and performance status (PS) should not be accompanied with pseudoprogression since it most probably reflects the true progression of the malignancy. ${ }^{7}$

Here we present the single institution experience of symptomatic pseudoprogression after one application of anti PD-L1 therapy in a patient with metastatic NSCLC followed by dramatic treatment response to immunotherapy and report on the review of symptomatic pseudoprogressions from literature.

\section{Methods}

A systematic review of the literature was made by using several electronic database: PubMed (US National Library of Medicine, http://www.ncbi. nlm.nih.gov/pubmed), Scopus (Elsevier, http:// www.scopus.com/), Google Scholar (https://scholar.google.it/), Web of Science (Thomson Reuters, http://apps.webofknowledge.com/), De Gruyter (https://www.degruyter.com/) and Cochrane Library (http://www.cochranelibrary.com/), with the following search criteria: symptomatic pseudoprogression, atypical response, immunotherapy and lung cancer.

\section{Results}

Altogether, five reports of seven patients treated with immunotherapy were identified that met the inclusion criteria (Table 1). ${ }^{17-21}$ In our analysis, three males and five females (including our case) were included with median age of 63 years (range 46-68). PD-L1 expression was reported in three patients, all treated with pembrolizumab. In all patients, good partial or almost complete response was observed between six and twelve weeks of treatment, that lasted at the time of report. All other patients with unknown PD-L1 expression were treated with nivolumab. Only one of them continued treatment for 12 months at the time of the report.

We present our case of 67 year-old female patient that was presented in September 2016 with primary metastatic lung adenocarcinoma of the left upper lobe with negative biopsy for epidermal growth factor receptor (EGFR) mutation, anaplas- tic lymphoma kinase (ALK) and ROS1 rearrangement. Due to extensive disease with metastases in the lung, axillary and abdominal lymph nodes, bones, left kidney and suprarenal gland with symptoms of pain in left hip, anorexia, fatigue and PS 2 she started treatment with urgent radiotherapy of the mediastinum, bulky mass on the left neck and left hip. After the pain was relieved with palliative radiotherapy, she started chemotherapy (ChT) with pemetrexed and carboplatin. Immediately after completing 4 cycles of ChT a progressive disease in the lung, right supraclavicular region, both suprarenal glands and subcutaneously was revealed, confirmed by FDG PET-CT (Figure 1). Aspiration biopsy of the lymph node in supraclavicular region was performed at that time and $100 \%$ of PD-L1 expression was found. While waiting for the result of PD-L1 expression her clinical condition worsened with aggravation of pain, muscle weakness, febrile state with no signs of infection and respiratory insufficiency. Nevertheless we decided to treat her with immunotherapy after her state was stabilized with supportive care. Her PS was scored as 2 at that time. In March $8^{\text {th }}$ 2017 she received first cycle of pembrolizumab. Two weeks later her condition aggravated to PS 4 with more pain, loss of appetite and occasional somnolence. Immunotherapy was stopped and she was referred to palliative care 22 days after $1^{\text {st }}$ cycle of pembrolizumab and thereafter lost from control. Three months later patient surprisingly called her oncologist. She was at home working in the garden with almost no pain, asking for continuation of treatment with pembrolizumad. On medical examination few days later in June 2017 she was in PS 1 and actually continued treatment with immunotherapy. One week after second dose of pembrolizumab on June 2017 FDG PETCT was performed and almost complete response was found (Figure 2). Patient continued treatment with immunotherapy and until February 2018 she received 13 doses with further clinical and radiological stable disease.

\section{Discussion}

To the best of our knowledge, we are the first that report on symptomatic pseudoprogression followed by almost complete response in a patient with metastatic NSCLC three months after one dose of checkpoint inhibitor. Immunotherapy has unique action and promotes immune system to incite inflammation directed to tumor with no direct 
TABLE 1. Symptomatic pseudo progression: review of the literature

\begin{tabular}{|c|c|c|c|c|c|c|c|c|c|c|}
\hline $\begin{array}{l}\text { Author, } \\
\text { (Year), } \\
\text { reference }\end{array}$ & $\begin{array}{l}\text { Sex/ } \\
\text { age } \\
\text { (years) }\end{array}$ & Histology & Initial stage & $\begin{array}{l}\text { Line of } \\
\text { systemic } \\
\text { therapy }\end{array}$ & $\begin{array}{l}\text { PD-LI } \\
\text { expression }\end{array}$ & Anti-PD-1/PD-L1 & Time to PP & Symptoms of PP & $\begin{array}{l}\begin{array}{l}\text { Time to } \\
\text { response } \\
\text { (months) }\end{array} \\
\end{array}$ & $\begin{array}{l}\text { Subsequent } \\
\text { treatment } \\
\text { (time) }\end{array}$ \\
\hline $\begin{array}{l}\text { Sarfay et al. } \\
(2016)^{17}\end{array}$ & $F / 68$ & $\begin{array}{l}\text { squamous } \\
\text { NSCLC }\end{array}$ & $\begin{array}{l}\text { locally } \\
\text { advanced }\end{array}$ & 2 & NR & nivolumab & 1 week & Pain, sys.inflam.reac. & 4 weeks & $\mathrm{NC}(6 \mathrm{~m})$ \\
\hline $\begin{array}{l}\text { Kolla et al. } \\
(2016)^{18}\end{array}$ & $\mathrm{M} / 46$ & $\begin{array}{l}\text { adenoca } \\
\text { EGFR } \\
\text { ex21 }\end{array}$ & metastatic & 11 & NR & $\begin{array}{l}\text { nivolumab } \\
\text { nivolumab }\end{array}$ & NR & $\begin{array}{l}\text { SVCS, stenting req., } \\
\text { Card. tamponade, } \\
\text { Pericard.req. } \\
\text { Card.tamponade, } \\
\text { Pericard.req. }\end{array}$ & 8 weeks & $\mathrm{NC}(12 \mathrm{~m})$ \\
\hline $\begin{array}{l}\text { Izumida et al. } \\
(2017)^{19}\end{array}$ & $M / 64$ & adenoca & metastatic & 6 & NR & nivolumab & 2 months & Gen.det. & 3 months & $\begin{array}{l}\text { IT S, } \\
\text { IT reint. (11m) }\end{array}$ \\
\hline $\begin{array}{l}\text { Kumagai et al. } \\
(2017)^{20}\end{array}$ & $F / 62$ & adenoca & $\begin{array}{l}\text { locally } \\
\text { advanced }\end{array}$ & 7 & NR & nivolumab & 12 weeks & $\begin{array}{l}\text { Hemoptysis, } \\
\text { art.embol.req. }\end{array}$ & 20 weeks & Pacli, S-1 \\
\hline $\begin{array}{l}\text { Hochmair et al. } \\
(2017)^{21}\end{array}$ & $\begin{array}{l}M / 63 \\
F / 63\end{array}$ & $\begin{array}{l}\text { adenoca } \\
\text { adenoca }\end{array}$ & $\begin{array}{l}\text { locally } \\
\text { advanced } \\
\text { metastatic }\end{array}$ & $\begin{array}{l}2 \\
2\end{array}$ & $\begin{array}{l}90 \% \\
\text { Highly }\end{array}$ & $\begin{array}{l}\text { pembrolizumab } \\
\text { pembrolizumab }\end{array}$ & $\begin{array}{l}2 \text { months } \\
4 \text { weeks }\end{array}$ & $\begin{array}{l}\text { Resp.insuf. (O2 req) } \\
\text { Gen.det., } \\
\text { Resp.insuf.(O2 req) }\end{array}$ & $\begin{array}{l}6 \text { weeks } \\
\text { after PP } \\
3 \text { months }\end{array}$ & $\begin{array}{l}N C(13 \mathrm{~m}) \\
N C(19 \mathrm{~m})\end{array}$ \\
\hline $\begin{array}{l}\text { Vrankar et al. } \\
(2018)\end{array}$ & $F / 67$ & adenoca & metastatic & 2 & $100 \%$ & pembrolizumab & 2 weeks & Gen.det., & 3 months & IT reint. (11m) \\
\hline
\end{tabular}

adenoca = adenocarcinoma; art.= arterial; card.= cardiac; det.= deterioration; embol.= embolization; ex 21 = exon 21 ; gen.= general; insuf.= insufficiency; IT = immunotherapy; $\mathrm{m}=$ months; $\mathrm{NC}=$ not changed; $\mathrm{NR}=$ not reported, osi = osimertinib; pacli = paclitaxel; pericard.= pericardiocentesis; PP = pseudo progression; req. required; reint.= reinitiated: resp.= respiratory; $S$ = stopped; $S-1$ = tegafur/gimeracil/oteracil; $S V C S=$ syndrome vena cava superior; sys.inflam.reac.= systemic inflammatory reaction

cytotoxic impact on the tumor growth. ${ }^{22}$ As a result, atypical responses are observed such as delayed responses, pseudoprogression, hyperprogression and abscopal effect. ${ }^{6}$ These unusual phenomenas could be explained by $\mathrm{T}$ cell recruitment and infiltration into the tumor together with edema and necrosis. ${ }^{13}$ Also, the time of immune activation and onset of clinical activity are not predictable yet.

In our case, symptomatic pseudoprogression was accompanied by delayed response after only one dose of check point inhibitor. This phenomena opens questions about appropriate timing, dosage and frequency of immunotherapy. PD-1 and PD-L1 inhibitors nivolumab, pembrolizumab and atezolizumab were recently approved for the treatment of advanced NSCLC and medical products are prescribed every two or three weeks. ${ }^{23-28}$ As immunotherapy harness the host immune system in targeting the tumor, it could also trigger systemic inflammatory response, which could be in some patients followed by vigorous deterioration of clinical and performance status. ${ }^{29}$ It seems that especially patients with high expression of PD-L1 might have extensive systemic inflammatory response and current prescribed schedule of immunotherapy cause overtreatment. A marker of systemic inflammatory response that was extensively studied is pretreatment neutrophil-to-lymphocyte ratio (NLR). ${ }^{30-32}$ In the retrospective cohort study of 175 patients with metastatic NSCLC treated with nivolumab, pretreatment NLR $\geq 5$ was associated with statistically inferior overall survival and pro-
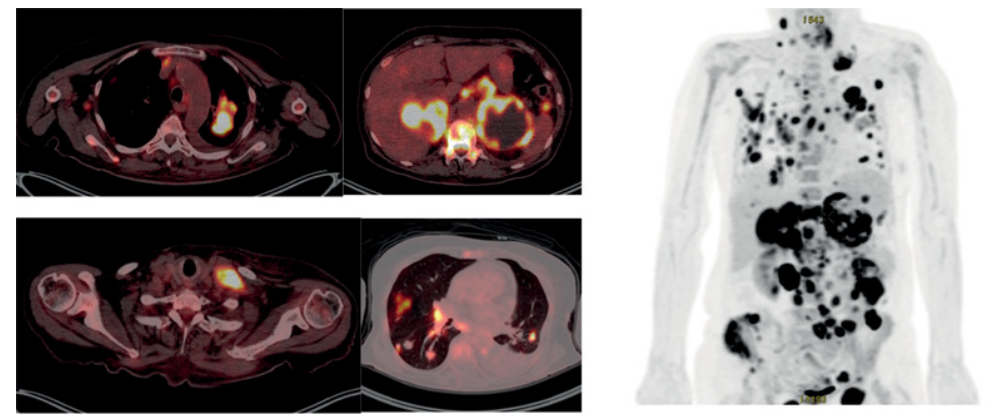

FIGURE 1. PET CT of non-small cell lung cancer patient from Institute of Oncology Ljubljana, at progression of disease after chemotherapy and before immunotherapy on March 2017.
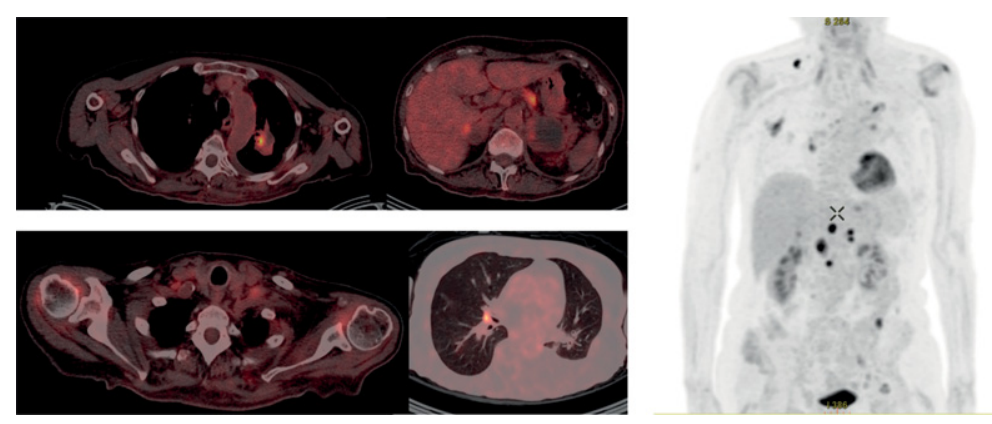

FIGURE 2. PET CT of non-small cell lung cancer patient from Institute of Oncology Ljubljana, three months after immunotherapy on June 2017.

gression free survival. ${ }^{33}$ NLR was not associated with response to nivolumab. In this cohort pseudoprogression was observed in $2.9 \%$ of patients. ${ }^{33}$ 
The differences in progression free survival (PFS) and overall survival (OS) related to NLR were also demonstrated in a study of metastatic melanoma patients treated with ipilimumab. ${ }^{34}$ Whether NLR is prognostic or predictive factor for OS is not clear and more data are needed for final conclusions.

In the literature we found 7 cases of patient with NSCLC treated with check point inhibitors that had evidence of pseudoprogression accompanied with worsening of clinical symptoms or PS. Five patients had worsening of disease-related symptoms that needed major intervention and had deterioration to PS 4. Treatment with checkpoint inhibitors was continued at the time of pseudoprogression since there was no alternative treatment options available. ${ }^{17,18,20,21}$ In spite of iRECIST recommended discontinuation of treatment in case of radiological pseudoprogression combined with deterioration of PS, all seven patients experienced improvement to PS 0-1. All patients had benefit from continuation of treatment and four of them were on treatment over 11 months.

Differentiation of pseudoprogression from true progression is a growing clinical challenge that could prevent from interruption of effective therapy or loosing time with ineffective treatment. Expression of PD-L1 is the most studied predictor biomarker for anti-PD-L1 therapy. ${ }^{35-37}$ Trials with pembrolizumab demonstrated improved outcomes in metastatic NSCLC patients with PD-L1 expression $\geq 50 \% .23,25$ Three patients in our review with symptomatic pseudoprogression that were treated with pembrolizumab had PD-L1 expression over $50 \%$. There are no clear data so far to connect incidence of pseudoprogression and high PD-L1 expression.

In few reports, pseudoprogression was confirmed with biopsy. In one of the cases, biopsy revealed fibrotic tissue with infiltrating $\mathrm{T}$ lymphocytes but no viable tumor cells and in second case, necrotic tissue with T cell infiltration was found. ${ }^{6}$ Biopsy is the most useful in distinguishing pseudoprogression from true progression. Unfortunately, the invasive procedures, which are usually needed, patients often refuse.

Most important imaging techniques used in daily clinical practice for evaluation of response to immunotherapy in NSCLC with iRECIST are CT, MRI and PET CT. ${ }^{16}$ Some other imaging technics and radiotracers are under investigation for better interpretation of atypical responses with immunotherapy. Dual Energy CT (DECT) can better revealed changes in the intratumoral vascularization, while Immuno-PET is a new metabolic imaging strategy that combine labeled monoclonal antibodies specific for T cells antigens. . $^{38,39}$

\section{Conclusions}

Uncommon response during immunotherapy is a challenging issue in the current oncology practice. As seen from our review, iRECIST criteria might be insufficient in distinguishing true progression from pseudoprogression in some cases, especially in patients with performance status deterioration. More precise assessment methods are urgently needed and some promising are under investigation. Besides iRECIST criteria, considering PD-L1 expression and histological features might be useful approach in clinical decision for immunotherapy continuation.

\section{References}

1. Pardoll DM. The blockade of immune checkpoints in cancer immunotherapy. Nat Rev Cancer 2012; 12: 252-64. doi: 10.1038/nrc3239

2. Brahmer J, Reckamp KL, Baas P, Crinò L, Eberhardt WE, Poddubskaya E, et al. Nivolumab versus docetaxel in advanced squamous-cell non-small-cell lung cancer. N Engl J Med 2015; 373: 123-35. doi: 10.1056/NEJMoa1504627

3. Borghaei H, Paz-Ares L, Horn L, Spigel DR, Steins M, Ready NE, et al. Nivolumab versus docetaxel in advanced nonsquamous non-small-cell lung cancer. N Engl J Med 2015; 373: 1627-39. doi: 10.1056/NEJMoa1507643

4. Garon EB, Rizvi NA, Hui R, Leighl N, Balmanoukian AS, Eder JP, et al. Pembrolizumab for the treatment of non-small-cell lung cancer. $N$ Engl $J$ Med 2015; 372: 2018-28. doi: 10.1056/NEJMoa1501824

5. Reck M, Rodríguez-Abreu $D$, Robinson AG, Hui R, Csőszi T, Fülöp A, et al. Pembrolizumab versus chemotherapy for PD-L1-positive non-small-cell lung cancer. N Engl J Med 2016; 375: 1823-33. doi: 10.1056/NEJMoa1606774

6. Wolchok JD, Hoos A, O'Day S, Weber JS, Hamid O, Lebbé C, et al. Guidelines for the evaluation of immune therapy activity in solid tumors: immune-related response criteria. Clin Cancer Res 2009; 15: 7412-20. doi: 10.1158/1078-0432.CCR-09-1624.

7. Seymour L, Bogaerts J, Perrone A, Ford R, Schwartz LH, Mandrekar S, et al. iRECIST: guidelines for response criteria for use in trials testing immunotherapeutics. Lancet Oncol 2017; 18: e143-52. doi: 10.1016/S14702045(17)30074-8

8. Hodi FS, Hwu WJ, Kefford R. Evaluation of immune-related response criteria and RECIST v1.1 in patients with advanced melanoma treated with pembrolizumab. J Clin Oncol 2016; 34: 1510-7. doi: 10.1200/JCO.2015.64.0391

9. Kurra V, Sullivan RJ, Gainor JF, Hodi FS, Gandhi L, Sadow CA, et al. Pseudoprogression in cancer immunotherapy: rates, time course and patient outcomes. [abstract]. J Clin Oncol 2016; 34(15 Suppl): No. 6580. doi: 10.1200/JCO.2016.34.15 suppl.6580

10. Hammer M, Bagley S, Aggarwal C, Bauml J, Nachiappan AC, Simone CB 2nd, et al. Thoracic imaging of non-small cell lung cancer treated with antiprogrammed death receptor-1 therapy. Curr Prob Diagn Radiol 2018 [Epub ahead of print]. doi: 10.1067/j.cpradiol.2018.01.005

11. Borghaei H, Paz-Ares L, Horn L, Spigel DR, Steins M, Ready NE, et al. Nivolumab versus docetaxel in advanced nonsquamous non-small-cell lung cancer. N Engl J Med 2015; 373: 1627-39. doi: 10.1056/NEJMoa1507643

12. Gettinger SN, Horn L, Gandhi L, Spigel DR, Antonia SJ, Rizvi NA, et al. Overall survival and long-term safety of nivolumab (anti-programmed death 1 antibody, BMS-936558, ONO-4538) in patients with previously treated advanced non-small-cell lung cancer. J Clin Oncol 2015; 33: 2004-12. doi: $10.1200 / J C O .2014 .58 .3708$ 
13. Chiou VL, Burotto M. Pseudoprogression and immune-related response in solid tumors. J Clin Oncol 2015; 33: 3541-3. doi: 10.1200/JCO.2015.61.6870

14. Nishino M, Ramaiya NH, Chambers ES, Adeni AE, Hatabu H, Jänne PA, et al. Immune-related response assessment during PD-1 inhibitor therapy in advanced non-small-cell lung cancer patients. J Immunother Cancer 2016; 4: 84. doi: 10.1186/s40425-016-0193-2

15. Kim HK, Heo MH, Lee HS, Sun JM, Lee SH, Ahn JS, et al. Comparison of RECIST to immune-related response criteria in patients with non-small cell lung cancer treated with immune-checkpoint inhibitors. Cancer Chemother Pharmacol 2017; 80: 591-8. doi: 10.1007/s00280-017-3396-4

16. Eisenhauer EA, Therasse P, Bogaerts J, Schwartz LH, Sargent D, Ford R, et al. New response evaluation criteria in solid tumours: revised RECIST guideline (version 1.1). Eur J Cancer 2009; 45: 228-47. doi: 10.1016/j.ejca.2008.10.026

17. Sarfaty M, Moore A, Dudnik E, Peled N. Not only for melanoma Subcutaneous pseudoprogression in lung squamous-cell carcinoma treated with nivolumab: a case report. Medicine (Baltimore) 2017; 96: e5951. doi: 10.1097/MD.0000000000005951

18. Kolla BC, Patel MR. Recurrent pleural effusions and cardiac tamponade as possible manifestations of pseudoprogression associated with nivolumab therapy - a report of two cases. J Immunother Cancer 2016 4: 80. doi: 10.1186/s40425-016-0185-2

19. Izumida T, Kawagishi Y, Tsuji H. Pseudoprogression in lung adenocarcinoma during treatment with nivolumab. BMJ Case Reports 2017; doi:10.1136/ bcr-2017-219919. [cited 2018 Feb 2]. Available at http://casereports.bmj. com/content/2017/bcr-2017-219919.full

20. Kumagai T, Kimura M, Inoue T, Tamiya M, Nishino K, Imamura F. Delayed pseudoprogression of lung adenocarcinoma accompanied with interstitial lung disease during chemotherapy after nivolumab treatment. Thorac Cancer 2017; 8: 275-7. doi: 10.1111/1759-7714.12431

21. Hochmair MJ, Schwab S, Burghuber OC, Krenbek D, Prosch H. Symptomatic pseudo-progression followed by significant treatment response in two lung cancer patients treated with immunotherapy. Lung Cancer 2017; 113: 4-6. doi: 10.1016/j.lungcan.2017.08.020

22. Schreiber RD, Old $\amalg$, Smyth MJ. Cancer immunoediting: integrating immunity's roles in cancer suppression and promotion. Science 2011; 331: 1565-70. doi: 10.1126/science.1203486

23. Garon EB, Naiyer AR, Hui R, Leighl N, Balmanoukian AS, Eder JP, et al. Pembrolizumab for the treatment of non-small-cell lung cancer. $N$ Engl J Med 2015; 372: 2018-28. doi: 10.1056/NEJMoa1501824

24. Brahmer J, Reckamp KL, Baas P, Crinò L, Eberhardt WEE, Poddubskaya E, et al. Nivolumab versus docetaxel in advanced squamous-cell non-small-cell lung cancer. N Engl J Med 2015; 373: 123-35. doi: 10.1056/NEJMoa1504627

25. Reck M, Rodríguez-Abreu D, Robinson AG, Hui R, Csőszi T, Fülöp $A$, et al. Pembrolizumab versus chemotherapy for PD-L1-positive non-small-cell lung cancer. N Engl J Med 2016; 375: 1823-33. doi: 10.1056/NEJMoa1606774

26. Rittmeyer A, Barlesi F, Waterkamp D, Park K, Ciardiello F, von Pawel J, et al. Atezolizumab versus docetaxel in patients with previously treated non-small-cell lung cancer (OAK): a phase 3 , open-label, multicentre randomised controlled trial. Lancet 2017; 389: 255-65. doi: 10.1016/SO1406736(16)32517-X

27. Fehrenbacher $L$, Spira A, Ballinger $M$, Kowanetz $M$, Vansteenkiste J, Mazieres J, et al. Atezolizumab versus docetaxel for patients with previously treated non-small-cell lung cancer (POPLAR): a multicentre, openlabel, phase 2 randomised controlled trial. Lancet 2016; 387: 1837-46. doi: 10.1016/S0140-6736(16)00587-0

28. Peters $S$, Gettinger S, Johnson ML, Jänne PA, Garassino MC, Christoph $D$, et al. Phase II trial of atezolizumab as first-line or subsequent therapy for patients with programmed death-ligand 1-selected advanced non-smallcell lung cancer (BIRCH). J Clin Oncol 2017; 35: 2781-9. doi: 10.1200/ JCO.2016.71.9476

29. Hanahan D, Weinberg RA. Hallmarks of cancer: the next generation. Cell 2011; 144: 646-74. doi: 10.1016/j.cell.2011.02.013

30. Guthrie GJ, Charles KA, Roxburgh CS, Horgan PG, McMillan DC, Clarke SJ. The systemic inflammation-based neutrophil-lymphocyte ratio: experience in patients with cancer. Crit Re Oncol Hematol 2013; 88: 218-30. doi: 10.1016/j.critrevonc.2013.03.010

31. Kang $\mathrm{MH}$, Go Sl, Song HN, Lee A, Kim SH, Kang JH, et al. The prognostic impact of the neutrophil-to-lymphocyte ratio in patients with small-cell lung cancer. Br J Cancer 2014; 111: 452-60. doi: 10.1038/bjc.2014.317
32. Templeton AJ, McNamara MG, Šeruga B, Vera-Badillo FE, Aneja P, Ocaña A, et al. Prognostic role of neutrophil-to-lymphocyte ratio in solid tumors: a systematic review and meta-analysis. J Natl Cancer Inst 2014; 106: dju124. doi: 10.1093/jnci/dju124

33. Bagley SJ, Kothari S, Aggarwal C, Bauml JM, Alley EW, Evans TL, et al. Pretreatment neutrophil-to-lymphocyte ratio as a marker of outcomes in nivolumab-treated patients with advanced non-small-cell lung cancer. Lung Cancer 2017; 106: 1-7. doi: 10.1016/j.lungcan.2017.01.013

34. Ferrucci PF, Gandini S, Battaglia A, Alfieri S, Di Giacomo AM, Giannarelli D, et al. Baseline neutrophil-to-lymphocyte ratio is associated with outcome of ipilimumab-treated metastatic melanoma patients. Br J Cancer 2015; 112: 1904-10. doi: 10.1038/bjc.2015.180

35. Vrankar M, Zwitter M, Kern I, Stanic K. PD-L1 expression can be regarded as prognostic factor for survival of non-small cell lung cancer patients after chemoradiotherapy. Neoplasma 2018; 59: 101-6. doi: 10.4149/ neo_2018_170206N77

36. Wang A, Wang HY, Liu Y, Zhao MC, Zhang HJ, Lu ZY, et al. The prognostic value of PD-L1 expression for non-small cell lung cancer patients: a metaanalysis. Eur J Surg Oncol 2015; 41: 450-6. doi:10.1016/j.ejso.2015.01.020

37. Zhou Z, Zhan P, Song Y. PD-L1 over-expression and survival in patients with non-small cell lung cancer : a meta-analysis. Transl Lung Cancer Res 2015; 4: 203-8. doi: 10.3978/j.issn.2218-6751.2015.03.02

38. Saba L, Poreu M, Schmid B, Flohr T. Dual energy CT: basic principles. In: Cecco CN, Laghi A, Schoepf UJ, Meinel FG, editors. Dual energy CT in oncology. Cham, Germany: Springer. p. 1-20.

39. Bensch F, Veen E, Jorritsma A. First-in-human PET imaging with the PD-L1 antibody 89Zr-atezolizumab. Paper presented at: AACR Annual Meeting, Washington Convention Center, April 2, 2017. СT017. 